\title{
Photophobia in migraine: an interictal PET study of cortical hyperexcitability and its modulation by pain
}

\author{
Nicolas Boulloche(1), Marie Denuelle (1), Pierre Payoux(2), Nelly Fabre(1), Yves
} Trotter(3)(4), Gilles Géraud(1)

(1) Service de Neurologie et Explorations Fonctionnelles du Système Nerveux, TSA 50032, CHU Rangueil, 31059 TOULOUSE Cedex 9, France

(2) INSERM U825, Université Paul Sabatier, CHU Purpan, TSA 50032, 31059 TOULOUSE Cedex 9, France

(3) Université de Toulouse 3, Centre de Recherche Cerveau et Cognition, UPS

(4) CNRS, UMR5549, Faculté de Médecine de Rangueil 31062 Toulouse Cedex 9, France

Corresponding author: Marie Denuelle

Corresponding author's address: Service de Neurologie et Explorations Fonctionnelles du Système

Nerveux, CHU Rangueil, 31059 TOULOUSE Cedex 9

Corresponding author's phone and fax: 0033561322642

Corresponding author's e-mail address: denuelle.m@chu-toulouse.fr

Keywords: Migraine, Cortical excitability, Photophobia, Trigeminal pain, Positron emitting tomography. Word count: 3189

The Corresponding Author has the right to grant on behalf of all authors and does grant on behalf of all authors, an exclusive licence (or non-exclusive for government employees) on a worldwide basis to the BMJ Publishing Group Ltd and its Licensees to permit this article (if accepted) to be published in Journal of Neurology, Neurosurgery \& Psychiatry and any other BMJPGL products to exploit all subsidiary rights, as set out in our licence (http://jnnp.bmj.com/ifora/licence.pdf). 


\section{ABSTRACT:}

Objective:

Photophobia is an abnormal sensitivity to light experienced by migraineurs and is perhaps caused by cortical hyperexcitability. In clinical studies, an interrelation between light perception and trigeminal nociception has been demonstrated in migraineurs but not in controls. The purpose of our study was to verify this interaction by functional imaging.

\section{Methods:}

We used $\mathrm{H}_{2} \mathrm{O}^{15}$ PET to study the cortical responses of seven migraineurs between attacks and the responses of seven matched control subjects to luminous stimulations at three luminance intensities: 0,600 and $1800 \mathrm{Cd} / \mathrm{m}^{2}$. All three intensities were both with and without concomitant trigeminal pain stimulation. In order to facilitate habituation, the stimulations were started 30 seconds before PET acquisitions.

\section{Results:}

When no concomitant pain stimulation was applied, luminous stimulations activated the visual cortex bilaterally in migraineurs (specifically in the cuneus, lingual gyrus, and posterior cingulate cortex) but not in controls. Concomitant pain stimulation allowed visual cortex activation in control subjects and potentiated its activation in migraineurs. These activations by luminous stimulations were luminanceintensity dependent in both groups. Concomitant stimulation by pain was associated with activation of the posterior parietal cortex (BA7) in migraineurs and controls.

\section{Interpretation:}

Our study shows the lack of habituation and/or cortical hyperexcitability to light in migraineurs. Moreover, the activation by light of several visual cortex areas (including the primary visual cortex) was potentiated by trigeminal pain, demonstrating multisensory integration in these areas. 


\section{INTRODUCTION:}

Photophobia accompanying migraine headaches is a symptom of important diagnostic value, and has been selected as one of the diagnostic criteria of migraine without aura by the International Headache Society (IHS). Its prevalence is about $85 \%$ of patients during attacks[1, 2], and it can also be present between attacks.[3] Some migraineurs even report bright or flickering lights as a trigger for their attacks,[4] and others report photophobia as a signal symptom that announces their attacks. The physiopathology of photophobia has been poorly studied and remains unknown.

Photophobia is defined as "hypersensitivity to light" by the IHS.[5] Indeed, some migraineurs report permanent visual discomfort between attacks.[6] Electrophysiological studies have led to the formulation of the hypothesis that there is a lack of habituation and/or a cortical hyper-excitability or hyper-responsiveness in migraine sufferers. $[7,8]$

Furthermore, there is an interrelationship between photophobia and pain. The migraine headache is considered as being due to the nociceptive activation of trigeminal cranial afferents from the meninges. A few experimental studies have confirmed an abnormal interrelationship between light perception and trigeminal nociception in migraineurs but not in controls. Pain stimulation in the ophthalmic territory of the trigeminal nerve decreased tolerance to light,[9] while light stimulation lowered the trigeminal nociceptive threshold.[10, 11]

The aim of this study has been to understand better these two aspects of photophobia in migraine: the cortical hyperexcitability and/or lack of habituation, and its interrelationship with trigeminal pain. In order to achieve this purpose, we used $\mathrm{H}_{2} \mathrm{O}^{15} \mathrm{PET}$ to observe cortical responses to visual stimuli in migraineurs and control subjects, both with and without concomitant trigeminal painful stimulation.

\section{MATERIALS AND METHODS:}

\section{Subjects:}

Seven female migraineurs ranging in age from 21 to 41 years (four with aura and three without aura, as defined by the IHS diagnosis criteria) were included in our study. All had fewer than six attacks a month (median=2), were always photophobic during attacks, had no other medical history than migraine, had never overused drugs, and had not been under any prophylaxis treatment for at least one year. Disease duration ranged from 1 to 34 years (median=18).

We included in our study seven age-matched female control subjects who had no first-order family history of migraine, no personal history of headache (particularly no history of tension-type headache), no medical history, and were not under any chronic treatment.

Investigators were not blinded to the diagnostic status of the subjects.

To test whether controls or migraineurs between their attacks were photophobic, they were asked to complete a validated visual discomfort auto-questionnaire.[12]

A cerebral magnetic nuclear resonance imaging (MRI) was performed and interpreted as normal in all subjects, with 3D T1WI gradient echo, T2WI gradient echo, FLAIRWI, diffusion WI, apparent diffusion coefficient cartography (1 Tesla Vision Magnetom, Siemens). 
A pregnancy test was performed prior to each Positron Emitting Tomography (PET) session. The study was approved by the local ethics committee. In accordance with the stipulations of the Helsinki Declaration, informed consent was obtained from each subject before the commencement of our study.

\section{Stimulations:}

Both the painfull and the luminous stimulations were continuous and were initiated 30 seconds before the beginning of each PET scan. Subjects were instructed to keep their eyes open and to avoid blinking during stimulations.

Luminous stimulations were performed through white, half-opaque, polyphane goggles covering the whole visual field, with no fixation point and neither spatial nor chromatic contrast. Three luminance intensities were applied through the goggles' surface: 0 (obscurity), 600 and $1800 \mathrm{Cd} / \mathrm{m}^{2}$. The light was produced by a halogen PAR64 spotlight with a 1000-Watt CP60 lamp. A transformer fitted with an ammeter allowed precise tuning of luminance intensity. Calibration of the system was verified by using a lux-meter (Minolta PS100).

Heat-pain stimulations were performed using a thermode (MSA Thermotest, Somedic AB) applied with constant pressure on the face, in the territory of the ophthalmic branch of the right trigeminal nerve (supra-orbital forehead).

In a preliminary session, which was performed at least three days from the last migraine attack and three days prior to the PET session, the temperature threshold inducing a pain of $30 \%$ of the maximum pain perceived was determined. The temperature threshold was determined specifically for each subject and in each lighting condition in order to take into account a modulation by light. The temperature was raised at the rate of $1^{\circ} \mathrm{C} / \mathrm{s}$ and a constant plateau was maintained for 30 seconds, at the end of which time subjects were asked to rate their pain between 0 to $100 \%$ of maximum pain. Stimulations were performed at different temperatures and were separated by 60 seconds of rest in obscurity. At rest, the temperature of the thermode was $35^{\circ} \mathrm{C}$.

During PET session, the temperature was increased, rising at the rate of $1^{\circ} \mathrm{C} / \mathrm{s}$ to attain the threshold, inducing a pain of $30 \%$ of maximum pain, which had been specifically determined for each subject and in each lighting condition. The plateau was maintained until the end of the acquisition (plateau's duration was 90 seconds).

\section{PET:}

The six conditions for migraineurs and control subjects were as follows: no pain and $0 \mathrm{Cd} / \mathrm{m}^{2}$ (NP0), no pain and $600 \mathrm{Cd} / \mathrm{m}^{2}$ (NP600), no pain and $1800 \mathrm{Cd} / \mathrm{m}^{2}$ (NP1800), pain and $0 \mathrm{Cd} / \mathrm{m}^{2}$ (P0), pain and $600 \mathrm{Cd} / \mathrm{m}^{2}$ (P600), pain and $1800 \mathrm{Cd} / \mathrm{m}^{2}$ (P1800). Conditions were randomised and duplicated in two consecutive blocks.

All PET sessions were performed at the same time of day, between 2 and 5 p.m. The PET session began with a 10-minute transmission scan at rest with neither painful nor visual stimulation 
(darkness) during which subjects could adapt to the room's conditions. Scans were started 30 seconds after the beginning of stimulations. Each acquisition consisted of two 30-second frames scanned by an EXACT HR+ camera (CT/Siemens, Knoxville TN) after an intra-veinous injection of $\sim 350 \mathrm{MBq}$ of $\mathrm{H}_{2} \mathrm{O}^{15}$ into the left arm. They were separated by 7 minutes of rest during which subjects were told that they could relax. The PET session was performed at least 3 days after the pain threshold preliminary session or migraine attack, and migraineurs were contacted 3 days after the PET session to check whether further migraine attacks had occurred.

Clinical data were collected at the end of each PET scan: subjects were asked to rate verbally the pain (percentage of maximum pain) and visual discomfort ( $0=$ none, 1 =light, $2=$ moderate or $3=$ severe) experienced during the PET scan.

\section{Statistical analysis:}

Clinical data were analysed using the Mann-Whitney U-test. As we had duplicated the six conditions in two blocks, variation of pain and visual discomfort ratings was defined for each condition as the difference in measure between the first and second block ratings.

PET data were analysed using SPM2 (http://www.fil.ion.ucl.ac.uk/spm) run on a Matlab platform (Mathworks Inc.). Images were normalized on the stereotaxic MNI (Montreal National Institute) template then smoothed with a $10 \mathrm{~mm}$ Gaussian kernel.

First-order analyses of the light effect were performed in a global linear generalized model including the six conditions of the two groups, with proportional scaling normalization for global cerebral blood flow changes. The following contrasts were studied in each group: NP1800-NP0, NP600-NP0, P1800P0, P600-P0. The significance of the activations was as follows: $p$ with False Discovery Rate (FDR) correction $<0.05$ and volume of activation $k>300$ voxels. The same methodology was used to construct individual models, allowing the extraction of individual first-order contrast for each subject, which were later used for second-order analyses.

Second-order analyses were performed in order to study the effect of light intensity and concomitant pain stimulation. Within-subject analysis of variance (ANOVA) allowed comparisons by SPM2 of the first-order individual contrasts. Two analyses were performed: one in control subjects, the other in migraineurs. Inter-group comparisons were second-order t-test comparisons of the first-order individual contrasts. Each second-order analysis was performed within the luminous-stimulationrelated volume; this was the mask of first-order activations by light in the global analysis for the appropriate subjects ( $p$ uncorrected $<0.05, k>10000$ voxels). The significance level for second-order analyses was as follows: $p$ uncorrected $<0.05$ and volume of activation $k>200$ voxels. The same methodology was used for the subgroup comparison of migraineurs with versus without aura.

Labelling of the activations in the Talairach and Tournoux atlas was facilitated by the use of MNI Space Utility SPM2 toolbox (http://www.ihb.spb.ru/ pet_lab/MSU/MSUMain.html). 


\section{RESULTS:}

\section{Clinical data during PET sessions}

The visual discomfort rating variation between the two blocks of duplicated conditions decreased in control subjects (mean $=-0.7$ ) while it increased in migraineurs (mean $=+0.9$ ). The difference between the two groups was significant $(p=0.031)$.

There was no significant difference between migraineurs and control subjects in pain rating and no clinical effect of pain on visual discomfort rating was observed.

\section{Activations by light (see Table 1 and Figures 1 and 2)}

In control subjects luminous stimulation did not produce any activation of the visual cortex when no concomitant pain was applied, neither at 600 nor at $1800 \mathrm{Cd} / \mathrm{m}^{2}$. With concomitant pain luminous stimulation produced an activation of the primary and secondary visual cortex (BA17 \& BA18) and the adjacent posterior cingulate cortex (BA30 \& BA31). At $1800 \mathrm{Cd} / \mathrm{m}^{2}$, the activation was larger and involved also the visual associative (BA19) and posterior parietal cortex (BA7).

In migraineurs visual cortex activation occurred with luminous stimulation even without concomitant pain. The volume of activations increased with increasing luminance intensity from 600 to 1800 $\mathrm{Cd} / \mathrm{m}^{2}$. In all conditions activations involved the primary and secondary visual cortex (BA17 \& BA18) and the adjacent posterior cingulate cortex (BA30 \& BA31). With concomitant pain the volume of activations was larger. With concomitant pain at 600 and $1800 \mathrm{Cd} / \mathrm{m}^{2}$, luminous stimulation produced activation in BA7 and BA19.

Z scores were similar in all activations but for the same statistical threshold the volume of the activations was larger in migraineurs than in control subjects. Second-order analyses allowed statistical comparison of those different activations.

\section{Intergroup comparison (see Table 2)}

As expected, when no concomitant pain was applied, activations by light were stronger in migraineurs than in controls in all the areas activated in migraineurs (BA17, BA18, BA30 \& BA31).

At $1800 \mathrm{Cd} / \mathrm{m}^{2}$ and with concomitant pain, activations happened in significantly different areas in migraineurs and control subjects. Luminous-stimulation-related activation was stronger in the secondary visual cortex (BA18) in migraineurs, whereas it was stronger in BA7 and BA19 in control subjects (see Figure 4).

At $600 \mathrm{Cd} / \mathrm{m}^{2}$ and with concomitant pain, no luminous-stimulation-related activation was significantly stronger in migraineurs.

\section{Effect of concomitant pain stimulation (see Table 3)}


In control subjects concomitant pain stimulation induced an increase of the luminous-stimulationrelated activation by light at 600 and $1800 \mathrm{Cd} / \mathrm{m}^{2}$ in primary and associative visual cortex (BA17, BA18 \& BA31). The activation by light of BA7 \& BA19 was potentiated by pain only at $1800 \mathrm{Cd} / \mathrm{m}^{2}$.

In migraineurs pain potentiated luminous-stimulation-related activation by light at 600 and 1800 $\mathrm{Cd} / \mathrm{m}^{2}$ in BA7 \& BA19.

\section{Effect of luminance intensity (see Table 4)}

Activation by light in the visual cortex was always stronger with 1800 than $600 \mathrm{Cd} / \mathrm{m}^{2}$ stimuli in migraineurs and control subjects. It was not possible to perform this analysis in control subjects when no pain was applied because, in this situation, luminous stimulations did not induce any activation. In addition to the visual cortex, the posterior parietal cortex (BA7) was affected by the effect of luminance intensity in control subjects but not in migraineurs.

\section{Other results}

Despite the fact that migraineurs had a slight higher visual discomfort auto-questionnaire score than controls (mean 14.9 versus 8.7), the difference between both groups was not significant.

There was no statistically significant difference between the activation by light of migraineurs with aura and migraineurs without aura.

\section{DISCUSSION:}

\section{Potentiation of visual cortex activation by pain in control subjects}

In control subjects luminous stimulation failed to induce visual cortex activation. This result had been anticipated because of the characteristics of the stimuli applied. All stimuli were continuous, without any contrast, and were started 30s before the scans. This should have facilitated habituation. Indeed, although our clinical evaluation was very basic $(0=$ none, $1=$ light, $2=$ moderate or $3=$ severe), visual discomfort decreased in control subjects throughout the PET session. This phenomenon could be explained by the physiology of the neurons of the visual system. In the retina, center/surround interaction in the receptor field of the ganglion cells attenuates light perception when there is no spatial or temporal contrast.[13] In the lateral geniculate nuclei, neurons have the same properties.[14] In the primary visual cortex, simple and complex cells, that would result from the summation of lateral geniculate nuclei aligned receptive fields[15, 16], are sensitive to simple characteristics of their receptive fields such as the spatial or temporal characteristics of oriented gratings, or the colour contrast, but do not respond when those contrasts are absent.[17]

Concomitant trigeminal pain stimulation induced activation of the visual cortex by light. This interaction may be specific to the ophthalmic territory of trigeminal nerve (V1) nociception. Indeed, clinical studies have shown just such an interaction since pain stimulation in the V1 territory decreased 
tolerance to light[10, 11] while light stimulation lowered the trigeminal nociceptive threshold.[9] This interaction may explain the photophobia in non-migraineurs which occurs when visual pathways and V1 nociception are damaged, as in the case of eye anterior segment diseases,[18, 19] optic nerve or peri-chiasmatic tumours,[20] sub-arachnoid haemorrhage and meningitis. Then photophobia may be due to visual cortex over-activation by light.

However this potentiation of the light-induced visual cortex activation by pain may not be specific to the V1 territory. Indeed, this phenomenon was described recently in the high-level visual cortex area in an object recognition study with concomitant pain stimulation of the hand.[21] The authors also observed an intermodal activation of the pregenual anterior cingulate cortex and interpreted their results as a modulation by attentional processes. We could suggest as an hypothesis that in our study pain reduced habituation to light through attentional processes.

\section{Effect of luminance intensity on visual cortex activation}

Visual cortex activations are usually dependent on stimulus intensity. For example, primary visual cortex responses depend on pattern contrast intensity [22] and middle temporal (MT) area responses depend on stimulus velocity.[23, 24] In our study activations occurred in response to luminous stimulation in all conditions in migraineurs and only when concomitant pain stimulation was performed in control subjects. These activations appeared to be dependent on the luminance intensity of the stimuli. For methodological reasons we were unable to test different pain intensities. Further studies are needed to determine whether these luminous-stimulation-related activations, which were painstimulation dependent, were modulated by luminous intensity AND pain intensity.

\section{Hyper-responsiveness of the visual cortex in migraineurs}

Without concomitant pain luminous-stimulation-related activations were present in migraineurs only. Migraineurs clearly showed greater luminous-stimulation-related activations than did control subjects. Indeed, these activations were greater in all but one condition $\left(600 \mathrm{Cd} / \mathrm{m}^{2}\right.$ with concomitant pain). It is difficult to interpret this result properly because of the nature of the stimuli we used. As we have seen, these stimuli facilitated habituation. Therefore it is impossible to know whether the differences between migraineurs and control subjects are due to a lack of habituation or to cortical hyperreponsiveness. However, our clinical data showed that visual discomfort increased during the study in migraineurs, while decreasing in controls. This suggests a habituation in controls as opposed to a sensitization in migraineurs.

Other functional neuro-imaging studies of visual cortex responses to light stimulation using functional MRI have yielded conflicting results. The intensity of activation of the visual cortex (measured as BOLD signal amplitude) in migraineurs was either higher,[25] similar,[26] or lower[27] than in

controls. These discrepancies might be due to variations in methodology and in the recruitment of subjects. Functional MRI is based on BOLD signal changes in response to repetitive stimuli. Habituation is a normal phenomenon which occurs as a consequence of the periodicity of the 
stimuli.[28] Differences in activation intensities might in fact be differences in habituation intensities, and might be explained by differences in methodology. Indeed, sensitivity to light differs between migraineurs and is not specific to migraine.[29, 30] Thus, due to the selection of subjects, sensitivity to light and habituation impairment may have overlapped in both groups, and hampered the conclusiveness of the results. One must keep in mind that increased light sensitivity is also present in tension-type headaches, and this type of headache is particularly frequent in the general population.[31] Moreover, habituation impairment might also have occurred in control subjects as it is present in first-order relatives of migraineurs, even though they are not migraineurs themselves.[32] In our study such biases were fully controlled: migraineurs were all photophobic during attacks, and control subjects were highly selected to avoid any overlap between the two groups.

\section{Differential activation of BA7 in migraineurs versus control subjects}

In our study the posterior parietal cortex (precuneus, BA7) was activated by luminous stimulation only when concomitant pain was applied (Tables 1 and 3). This activation differed in migraineurs and controls. In migraineurs BA7 was activated at all luminance levels but was not strong enough to be significant when compared with controls (Table 2). In control subjects, BA7 activation happened only at $1800 \mathrm{Cd} / \mathrm{m}^{2}$ and was stronger than in migraineurs.

BA7 has been reported as being activated by attentional and working memory tasks, particularly topdown spatial attention.[33, 34] In our study there was no such attention task. Moreover, our visual stimuli were purely luminous, without any component of movement, shape or colour. In both groups we observed that BA7 was activated by luminous stimulations only when concomitant pain was applied. This suggests that pain induced an attentional response to luminous stimuli.

The parallel with psychophysical studies is striking. In those studies migraineurs had lower performances than control subjects in visual attentional tasks such as the detection of moving dots.[35, 36] We can assume that the patterns of the stimuli used in those studies may have been responsible for visual discomfort in migraineurs. Some authors have suggested that visual discomfort induced by stimuli may unspecifically capture attention and be responsible for lower performance than in controls.[30, 37] Our study agrees with this hypothesis, showing a hyper-responsiveness of the visual cortex in relation to a difference in modulation by top-down attentional processes.

This difference between migraineurs and controls in the top-down modulation by BA7 can easily fit in with current models of migraine pathogenesis. It has been shown that motivational salience is mediated by subcortical structures, including locus coeruleus.[38] More-over, locus coeruleus modulates nociception.[39, 40] Locus coeruleus has diffuse cortical efferences and its role may be considered as enhancing global neuronal responses to stimuli. But it has been shown recently that it interacts with the visuo-spatial attention network, including the posterior parietal cortex (BA7), to encode the motivational salience.[41] Given the role of subcortical structures such as locus coeruleus in migraine pathogenesis,[42] we can hypothesize that these structures could be involved in the potentiation by pain of the visual cortex activation, directly or via BA7. 


\section{CONCLUSION:}

This study shows a stronger activation of the visual cortex in response to luminous stimulation in migraineurs in comparison with the activation elicited from control subjects. Indeed, no visual cortex activation was recorded in control subjects when no concomitant pain was applied. This phenomenon may rely on the habituation induced by the long lasting stimuli we used. Moreover, our results demonstrate a potentiation by pain of visual cortex responses to luminous stimulation in both groups, possibly by attenuating this habituation.

\section{ACKNOWLEGMENTS:}

We would like to thank the TEP Centre of Toulouse for their participation and encouragement, and the Clinical Investigation Centre for the management of the patients.

This work was supported by a grant from the Délégation Régionale à la Recherche Clinique des Hôpitaux de Toulouse 2005.

\section{BIBLIOGRAPHY:}

1 Morillo LE, Alarcon F, Aranaga N, et al. Clinical Characteristics and Patterns of Medication Use of Migraneurs in Latin America from 12 Cities in 6 Countries. Headache. 2005;45(2):118-26.

2 Aygul R, Deniz O, Kocak N, et al. The Clinical Properties of a Migrainous Population in Eastern Turkey-Erzurum. South Med J. 2005;98(1):23-7.

3 Main A, Dowson A, Gross M. Photophobia and Phonophobia in Migraineurs between Attacks. Headache. 1997;37(8):492-5.

4 Cao Y, Aurora SK, Nagesh V, et al. Functional Mri-Bold of Brainstem Structures During Visually Triggered Migraine. Neurology. 2002;59(1):72-8.

5 Olesen J, Diener HC, Dodick D, et al. The International Classification of Headache Disorders. Cephalalgia. 2004;24(S1):1-150.

6 Vanagaite J, Pareja JA, Storen O, et al. Light-Induced Discomfort and Pain in Migraine. Cephalalgia. 1997;17(7):733-41.

7 Ambrosini A, de Noordhout AM, Sandor PS, et al. Electrophysiological Studies in Migraine: A Comprehensive Review of Their Interest and Limitations. Cephalalgia. 2003;23 Suppl 1:13-31.

8 Aurora SK, Wilkinson F. The Brain Is Hyperexcitable in Migraine. Cephalalgia. 2007;27(12):144253.

9 Drummond PD, Woodhouse A. Painful Stimulation of the Forehead Increases Photophobia in Migraine Sufferers. Cephalalgia. 1993;13(5):321-4.

10 Drummond PD. Photophobia and Autonomic Responses to Facial Pain in Migraine. Brain. 1997;120 ( Pt 10):1857-64.

11 Kowacs PA, Piovesan EJ, Werneck LC, et al. Influence of Intense Light Stimulation on Trigeminal and Cervical Pain Perception Thresholds. Cephalalgia. 2001;21(3):184-8.

12 Conlon E, Lovegrove W, Chekaluk E, et al. Measuring Visual Discomfort. Visual Cognition. 1999;(6):637-63. 
13 Maffei L. Inhibitory and Facilitatory Spatial Interactions in Retinal Receptive Fields. Vision Res. 1968;8(9):1187-94.

14 Hubel DH, Livingstone MS. Color and Contrast Sensitivity in the Lateral Geniculate Body and Primary Visual Cortex of the Macaque Monkey. J Neurosci. 1990;10(7):2223-37.

15 Chapman B, Zahs KR, Stryker MP. Relation of Cortical Cell Orientation Selectivity to Alignment of Receptive Fields of the Geniculocortical Afferents That Arborize within a Single Orientation Column in Ferret Visual Cortex. J Neurosci. 1991;11(5):1347-58.

16 Hubel DH, Wiesel TN. Receptive Fields, Binocular Interaction and Functional Architecture in the Cat's Visual Cortex. J Physiol. 1962;160:106-54.

17 DeYoe EA, Van Essen DC. Concurrent Processing Streams in Monkey Visual Cortex. Trends Neurosci. 1988;11(5):219-26.

18 Trobe JD. Photophobia in Anterior Visual Pathway Disease. J Neuroophthalmol. 2002;22(1):1-2.

19 Lee AG, Miller NR. Photophobia in Anterior Visual Pathway Lesions. J Neuroophthalmol. 2003;23(1):106; author reply

20 Kawasaki A, Purvin VA. Photophobia as the Presenting Visual Symptom of Chiasmal Compression. J Neuroophthalmol. 2002;22(1):3-8.

21 Bingel U, Rose M, Glascher J, et al. Fmri Reveals How Pain Modulates Visual Object Processing in the Ventral Visual Stream. Neuron. 2007;55(1):157-67.

22 Albrecht DG, Hamilton DB. Striate Cortex of Monkey and Cat: Contrast Response Function. ] Neurophysiol. 1982;48(1):217-37.

23 Felleman DJ, Kaas JH. Receptive-Field Properties of Neurons in Middle Temporal Visual Area (Mt) of Owl Monkeys. J Neurophysiol. 1984;52(3):488-513.

24 Priebe NJ, Cassanello CR, Lisberger SG. The Neural Representation of Speed in Macaque Area Mt/V5. J Neurosci. 2003;23(13):5650-61.

25 Huang J, Cooper TG, Satana B, et al. Visual Distortion Provoked by a Stimulus in Migraine Associated with Hyperneuronal Activity. Headache. 2003;43(6):664-71.

26 Huang J, DeLano M, Cao Y. Visual Cortical Inhibitory Function in Migraine Is Not Generally Impaired: Evidence from a Combined Psychophysical Test with an Fmri Study. Cephalalgia. 2006;26(5):554-60.

27 Bramanti P, Grugno R, Vitetta A, et al. Migraine with and without Aura: Electrophysiological and Functional Neuroimaging Evidence. Funct Neurol. 2005;20(1):29-32.

28 Parkes LM, Fries P, Kerskens CM, et al. Reduced Bold Response to Periodic Visual Stimulation. Neuroimage. 2004;21(1):236-43.

29 Shepherd AJ. Visual Contrast Processing in Migraine. Cephalalgia. 2000;20(10):865-80.

30 Conlon $\mathrm{E}$, Hine T. The Influence of Pattern Interference on Performance in Migraine and Visual Discomfort Groups. Cephalalgia. 2000;20(8):708-13.

31 Vanagaite Vingen J, Stovner L]. Photophobia and Phonophobia in Tension-Type and Cervicogenic Headache. Cephalalgia. 1998;18(6):313-8.

32 Sandor PS, Afra J, Proietti-Cecchini A, et al. Familial Influences on Cortical Evoked Potentials in Migraine. Neuroreport. 1999;10(6):1235-8.

33 Corbetta M, Miezin FM, Shulman GL, et al. A Pet Study of Visuospatial Attention. J Neurosci. 1993;13(3):1202-26.

34 Nobre AC, Sebestyen GN, Gitelman DR, et al. Functional Localization of the System for Visuospatial Attention Using Positron Emission Tomography. Brain. 1997;120 ( Pt 3):515-33.

35 Antal A, Temme J, Nitsche MA, et al. Altered Motion Perception in Migraineurs: Evidence for Interictal Cortical Hyperexcitability. Cephalalgia. 2005;25(10):788-94. 
36 Ditchfield JA, McKendrick AM, Badcock DR. Processing of Global Form and Motion in Migraineurs. Vision Res. 2006; 46(1-2):141-8.

37 Conlon E, Lovegrove W, Hine T, et al. The Effects of Visual Discomfort and Pattern Structure on Visual Search. Perception. 1998;27(1):21-33.

38 Aston-Jones G, Rajkowski J, Kubiak P. Conditioned Responses of Monkey Locus Coeruleus Neurons Anticipate Acquisition of Discriminative Behavior in a Vigilance Task. Neuroscience. 1997;80(3):697-715.

39 Matsutani K, Tsuruoka M, Shinya A, et al. Stimulation of the Locus Coeruleus Suppresses Trigeminal Sensorimotor Function in the Rat. Brain Res Bull. 2000;53(6):827-32.

40 Tsuruoka M, Matsutani K, Maeda M, et al. Coeruleotrigeminal Inhibition of Nociceptive Processing in the Rat Trigeminal Subnucleus Caudalis. Brain Res. 2003;993(1-2):146-53.

41 Mohanty A, Gitelman DR, Small DM, et al. The Spatial Attention Network Interacts with Limbic and Monoaminergic Systems to Modulate Motivation-Induced Attention Shifts. Cereb Cortex. 2008.

42 Goadsby PJ, Edvinsson L. The Trigeminovascular System and Migraine: Studies Characterizing Cerebrovascular and Neuropeptide Changes Seen in Humans and Cats. Ann Neurol. 1993;33(1):48-56. 


\section{LEGENDS:}

Figure 1: Activations by light. This figure summarizes the main results of the study: volumes of activation of visual cortex induced by light in both groups ( $\square$ migraineurs, $\square$ controls) as a function of pain conditions (No Pain, Pain) in both light intensities ( $\mathbb{Z} 600 \mathrm{Cd} / \mathrm{m}^{2}, \square 1800 \mathrm{Cd} / \mathrm{m}^{2}$ ).

Figure 2: Activations by light at $1800 \mathbf{~ C d} / \mathbf{m}^{2}$. Axial cross-sections at $z=0, z=8, z=16$ and $z=24$. Activations were in the cuneus, lingual gyrus, posterior cingulate cortex and precuneus. Note that the volume of activation is greater in migraineurs and that the activation in controls is more rostral.

Figure 3: Activation of BA7 (precuneus). Controls > Migraineurs intergroup comparison of activation by luminous stimulation at $1800 \mathrm{Cd} / \mathrm{m}^{2}$ with concomitant pain stimulation. Second-order analysis within the assumption mask, $p$ uncorrected $<0.05$, volume $k>200$ voxels, $x=10$. 


\begin{tabular}{|c|c|c|c|c|c|c|c|c|c|c|c|c|c|c|}
\hline \multirow{3}{*}{$\begin{array}{l}\text { Contrast: } \\
\text { No Pain: } \\
\quad 600-0 \mathrm{~cd} / \mathrm{m}^{2}\end{array}$} & \multicolumn{7}{|c|}{ CONTROLS } & \multicolumn{7}{|c|}{ MIGRAINEURS } \\
\hline & $\begin{array}{l}\text { Area of } \\
\text { activation }\end{array}$ & BA & $\begin{array}{l}\text { Volume } \\
\text { (voxels) }\end{array}$ & Z score & & $\begin{array}{l}\text { cool } \\
y \quad z\end{array}$ & & $\begin{array}{l}\text { Area of } \\
\text { activation }\end{array}$ & BA & $\begin{array}{l}\text { Volume } \\
\text { (voxels) }\end{array}$ & Z score & & $\begin{array}{l}\text { cool } \\
y \quad z\end{array}$ & \\
\hline & \multicolumn{7}{|c|}{ No significant activation } & $\begin{array}{l}\text { Cuneus } \\
\text { Linqual gyrus }\end{array}$ & $\begin{array}{l}17 \\
18\end{array}$ & 515 & $\begin{array}{l}5.75 \\
4.71\end{array}$ & $\begin{array}{r}4 \\
14\end{array}$ & $\begin{array}{l}-88 \\
-82\end{array}$ & $\begin{array}{r}-4 \\
2\end{array}$ \\
\hline $1800-0 \mathrm{Cd} / \mathrm{m}^{2}$ & \multicolumn{7}{|c|}{ No significant activation } & $\begin{array}{l}\text { Cuneus } \\
\text { Lingual gyrus } \\
\text { PCC }\end{array}$ & $\begin{array}{c}17 \\
18 \\
30 / 31\end{array}$ & 1504 & $\begin{array}{l}5.41 \\
5.07 \\
4.78\end{array}$ & $\begin{array}{r}-6 \\
-4 \\
6\end{array}$ & $\begin{array}{l}-72 \\
-78 \\
-86\end{array}$ & $\begin{array}{r}8 \\
14 \\
-2\end{array}$ \\
\hline $\begin{array}{l}\text { Pain: } \\
\qquad 600-0 \mathrm{~cd} / \mathrm{m}^{2}\end{array}$ & $\begin{array}{l}\text { Cuneus } \\
\text { Lingual gyrus } \\
\text { PCC }\end{array}$ & $\begin{array}{c}17 \\
18 \\
30 / 31\end{array}$ & 688 & $\begin{array}{l}5.22 \\
4.43 \\
3.76\end{array}$ & $\begin{array}{r}-8 \\
-18 \\
0\end{array}$ & $\begin{array}{l}-74 \\
-76 \\
-92\end{array}$ & $\begin{array}{r}8 \\
20 \\
16\end{array}$ & $\begin{array}{l}\text { Cuneus } \\
\text { Lingual gyrus } \\
\text { PCC } \\
\text { Precuneus }\end{array}$ & $\begin{array}{c}17 \\
18 \\
31 \\
19 / 7\end{array}$ & 1359 & $\begin{array}{l}5.41 \\
5.07 \\
4.78\end{array}$ & $\begin{array}{r}-10 \\
-2 \\
10\end{array}$ & $\begin{array}{l}-70 \\
-96 \\
-82\end{array}$ & $\begin{array}{r}10 \\
6 \\
18\end{array}$ \\
\hline $1800-0 \mathrm{Cd} / \mathrm{m}^{2}$ & $\begin{array}{l}\text { Cuneus } \\
\text { Lingual gyrus } \\
\text { PCC } \\
\text { Precuneus }\end{array}$ & $\begin{array}{c}17 \\
18 \\
30 / 31 \\
19 / 7\end{array}$ & 2123 & $\begin{array}{l}5.44 \\
5.32 \\
4.88\end{array}$ & $\begin{array}{l}4 \\
4 \\
6\end{array}$ & $\begin{array}{l}-94 \\
-84 \\
-84\end{array}$ & $\begin{array}{l}24 \\
22 \\
46\end{array}$ & $\begin{array}{l}\text { Cuneus } \\
\text { Lingual gyrus } \\
\text { PCC } \\
\text { Precuneus }\end{array}$ & $\begin{array}{c}17 \\
18 \\
30 / 31 \\
19 / 7\end{array}$ & 2723 & $\begin{array}{l}5.60 \\
5.44 \\
5.31\end{array}$ & $\begin{array}{r}14 \\
-10 \\
4\end{array}$ & $\begin{array}{l}-78 \\
-68 \\
-90\end{array}$ & $\begin{array}{l}6 \\
8 \\
6\end{array}$ \\
\hline
\end{tabular}

Table 1: Activations by light. p FDR corrected $<0.05$, volume $k>300$ voxels. BA: Brodmann Area. MNI coord: Coordinates in the Montreal National Institute template. PCC: Posterior Cingulate Cortex. 


\begin{tabular}{|c|c|c|c|c|c|c|c|c|c|c|c|c|}
\hline \multirow{4}{*}{$\begin{array}{l}\text { Condition: } \\
\text { No Pain: } \\
\quad 600 \mathrm{Cd} / \mathrm{m}^{2}\end{array}$} & \multicolumn{6}{|c|}{ CONTROLS versUS MIGRAINEURS } & \multicolumn{6}{|c|}{ MIGRAINEURS versus CONTROLS } \\
\hline & \multirow[t]{2}{*}{$\begin{array}{l}\text { Area of } \\
\text { activation }\end{array}$} & BA & Z score & \multicolumn{3}{|c|}{$\begin{array}{l}\text { MNI coord. } \\
\left(\begin{array}{lll}x & y & z\end{array}\right)\end{array}$} & \multirow[t]{2}{*}{$\begin{array}{l}\text { Area of } \\
\text { activation }\end{array}$} & BA & Z score & \multicolumn{3}{|c|}{$\begin{array}{l}\text { MNI coord. } \\
\left(\begin{array}{lll}x & y & z\end{array}\right)\end{array}$} \\
\hline & \multirow{2}{*}{\multicolumn{6}{|c|}{ No significant activation }} & & & & & & \\
\hline & & & & & & & Cuneus & 17 & 17 & 6 & -90 & \\
\hline $1800 \mathrm{~cd} / \mathrm{m}^{2}$ & \multirow{2}{*}{\multicolumn{6}{|c|}{ No significant activation }} & Cuneus & 17 & 3.16 & 14 & -66 & \\
\hline & & & & & & & Lingual gyrus & 18 & 3.04 & 2 & -102 & 10 \\
\hline \multirow{4}{*}{$\begin{array}{l}\text { Pain: } \\
\qquad 600 \mathrm{Cd} / \mathrm{m}^{2}\end{array}$} & & & & & & & \multirow{4}{*}{\multicolumn{6}{|c|}{ No significant activation }} \\
\hline & & & 3.64 & 2 & -64 & -14 & & & & & & \\
\hline & Cerebellum & & 3.07 & 8 & -64 & -26 & & & & & & \\
\hline & & & 2.38 & 4 & -56 & -22 & & & & & & \\
\hline \multirow[t]{3}{*}{$1800 \mathrm{Cd} / \mathrm{m}^{2}$} & & & 2.89 & 10 & -82 & 48 & \multirow{3}{*}{ Lingual gyrus } & \multirow{3}{*}{18} & 3.82 & 4 & -76 & -8 \\
\hline & Precuneus & $19 / 7$ & 2.80 & 4 & -86 & 34 & & & 3.49 & 6 & -90 & -16 \\
\hline & & & 2.76 & 6 & -80 & 40 & & & 2.76 & 10 & -82 & 4 \\
\hline
\end{tabular}

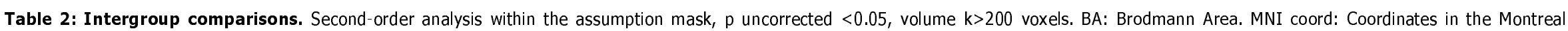
National Institute template. PCC: Posterior Cingulate Cortex. 


\begin{tabular}{|c|c|c|c|c|c|c|c|c|c|c|c|c|}
\hline \multirow{3}{*}{$\begin{array}{l}\text { Contrast: } \\
\text { Pain-No Pain } \\
\text { At } 600 \mathrm{Cd} / \mathrm{m}^{2}\end{array}$} & \multicolumn{6}{|c|}{ CONTROLS } & \multicolumn{6}{|c|}{ MIGRAINEURS } \\
\hline & \multirow{2}{*}{$\begin{array}{l}\begin{array}{l}\text { Area of } \\
\text { activation }\end{array} \\
\text { Cuneus } \\
\text { Lingual gyrus } \\
\text { PCC }\end{array}$} & \multirow[b]{2}{*}{$\begin{array}{l}\text { BA } \\
17 \\
18 \\
31\end{array}$} & \multirow{2}{*}{$\begin{array}{c}\text { Z score } \\
3.81 \\
3.58 \\
3.33\end{array}$} & \multicolumn{3}{|c|}{$\begin{array}{l}\text { MNI coord. } \\
\left(\begin{array}{lll}x & y & z\end{array}\right)\end{array}$} & \multirow{2}{*}{$\begin{array}{l}\text { Area of } \\
\text { activation } \\
\text { Cuneus } \\
\text { Precuneus } \\
\text { PCC } \\
\text { Lingual gyrus }\end{array}$} & \multirow[b]{2}{*}{$\begin{array}{c}\text { BA } \\
18 \\
19 / 7 \\
30 / 31\end{array}$} & \multirow{2}{*}{$\begin{array}{c}\text { Z score } \\
3.23 \\
2.00 \\
3.14 \\
2.20\end{array}$} & \multicolumn{3}{|c|}{$\begin{array}{l}\text { MNI coord. } \\
\left(\begin{array}{lll}x & y & z\end{array}\right)\end{array}$} \\
\hline & & & & $\begin{array}{r}-6 \\
-16 \\
4\end{array}$ & $\begin{array}{l}-76 \\
-70 \\
-86\end{array}$ & $\begin{array}{r}6 \\
20 \\
8\end{array}$ & & & & $\begin{array}{r}20 \\
10 \\
-10 \\
0\end{array}$ & $\begin{array}{l}-82 \\
-84 \\
-70 \\
-68\end{array}$ & $\begin{array}{r}24 \\
18 \\
8 \\
6\end{array}$ \\
\hline At $1800 \mathrm{Cd} / \mathrm{m}^{2}$ & $\begin{array}{l}\text { Cuneus } \\
\text { Lingual gyrus } \\
\text { PCC } \\
\text { Cuneus } \\
\text { Precuneus }\end{array}$ & $\begin{array}{l}17 \\
18 \\
31\end{array}$ & $\begin{array}{l}3.84 \\
3.45 \\
3.43 \\
3.42 \\
3.38 \\
2.87 \\
\end{array}$ & $\begin{array}{r}-6 \\
-8 \\
-16 \\
4 \\
10 \\
2 \\
\end{array}$ & $\begin{array}{l}-74 \\
-86 \\
-68 \\
-74 \\
-82 \\
-88 \\
\end{array}$ & $\begin{array}{l}10 \\
10 \\
20 \\
40 \\
48 \\
28 \\
\end{array}$ & $\begin{array}{l}\text { Cuneus } \\
\text { Precuneus }\end{array}$ & $\begin{array}{c}18 / 19 / \\
7 / 31\end{array}$ & $\begin{array}{l}3.27 \\
2.44 \\
2.22\end{array}$ & $\begin{array}{l}18 \\
30 \\
24\end{array}$ & $\begin{array}{l}-84 \\
-78 \\
-68\end{array}$ & $\begin{array}{l}26 \\
18 \\
24\end{array}$ \\
\hline
\end{tabular}

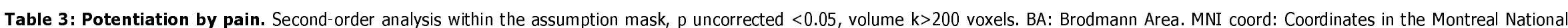
Institute template. PCC: Posterior Cingulate Cortex. 


\begin{tabular}{|c|c|c|c|c|c|c|c|c|c|c|c|c|}
\hline \multirow{3}{*}{$\begin{array}{l}\text { Contrast: } \\
\mathbf{1 8 0 0 - 6 0 0} \\
\text { Without pain }\end{array}$} & \multicolumn{6}{|c|}{ CONTROLS } & \multicolumn{6}{|c|}{ MIGRAINEURS } \\
\hline & \multirow[t]{2}{*}{$\begin{array}{l}\text { Area of } \\
\text { activation }\end{array}$} & \multirow[t]{2}{*}{ BA } & Z score & \multicolumn{3}{|c|}{$\begin{array}{l}\text { MNI coord. } \\
\left(\begin{array}{lll}x & y & z\end{array}\right)\end{array}$} & \multirow{2}{*}{$\begin{array}{l}\begin{array}{l}\text { Area of } \\
\text { activation }\end{array} \\
\text { Cuneus } \\
\text { PCC }\end{array}$} & \multirow{2}{*}{\begin{tabular}{|c|} 
BA \\
18 \\
$30 / 31$
\end{tabular}} & \multirow{2}{*}{$\begin{array}{c}\text { z score } \\
3.52 \\
3.28 \\
3.19 \\
\end{array}$} & \multicolumn{3}{|c|}{$\begin{array}{l}\text { MNI coord. } \\
\left(\begin{array}{lll}x & y & z\end{array}\right)\end{array}$} \\
\hline & & & vation to $\mathrm{C}$ & pare & & & & & & $\begin{array}{l}-2 \\
-6 \\
-2\end{array}$ & $\begin{array}{r}-82 \\
-68 \\
-102\end{array}$ & $\begin{array}{r}22 \\
2 \\
14\end{array}$ \\
\hline With pain & $\begin{array}{l}\text { Cuneus } \\
\text { Precuneus }\end{array}$ & $\begin{array}{c}18 \\
7 / 19\end{array}$ & $\begin{array}{l}3.21 \\
2.97 \\
2.58 \\
\end{array}$ & $\begin{array}{l}8 \\
8 \\
2 \\
\end{array}$ & $\begin{array}{l}-82 \\
-80 \\
-92 \\
\end{array}$ & $\begin{array}{l}50 \\
18 \\
32 \\
\end{array}$ & Cuneus & $18 / 19$ & $\begin{array}{l}2.89 \\
2.80 \\
2.57 \\
\end{array}$ & $\begin{array}{r}-2 \\
-4 \\
-12 \\
\end{array}$ & $\begin{array}{l}-92 \\
-82 \\
-80 \\
\end{array}$ & $\begin{array}{l}18 \\
20 \\
22 \\
\end{array}$ \\
\hline
\end{tabular}

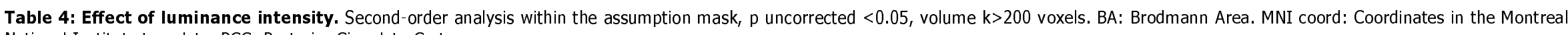
National Institute template. PCC: Posterior Cingulate Cortex. 


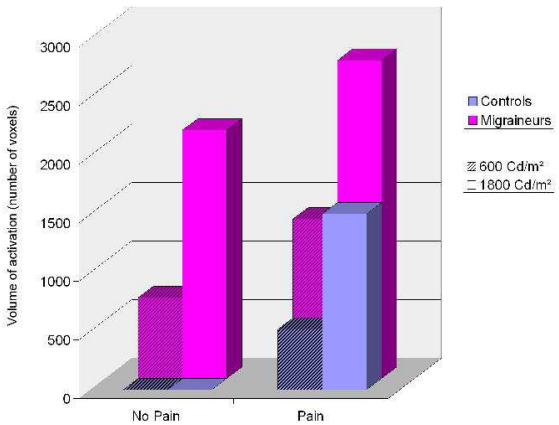




\section{CONTROLS}
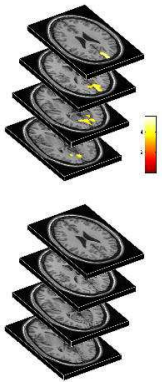

\section{MIGRAINEURS}

PAIN

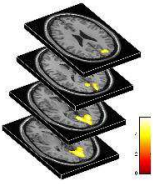

NO

PAIN

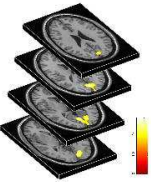




\section{(1)}

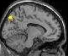

